\title{
The postage stamp as messenger
}

\author{
Robert A Greenwald
}

There was a gala birthday party in London on 6 May 1990; it was the sesquicentennial, or 150 th anniversary, of the invention of the postage stamp. An everyday item, taken for granted by routine users billions of times a day, the postage stamp was actually a radical and controversial item when it was introduced on 6 May 1840.

Postal systems have existed for millennia; the ancient kings of Persia had a mail system, and mail systems flourished in Europe in the Middle Ages. They were mainly the province of the king for his benefit both in making exorbitant profit and for communicating with the nobility. By coincidence, it was exactly 500 years before, in 1490, that the middle class and merchants were first allowed to use the postal system in western Europe.

There were three major differences between the postal rate system in use before and after 1840. Firstly, it was the recipient, not the sender, who paid the postage. Secondly, the rate tables were extraordinarily complex, and postal clerks had to spend substantial amounts of time calculating postage on non-routine letters, especially those with more than one sheet, that were heavier than normal, or traversed boundaries. Thirdly, the rates were enormous, and many mailers went to great lengths to avoid paying anything at all by taking advantage of a system of free franking privileges.

In North America today it takes under two minutes for an employee making $\$ 10$ an hour to earn enough money to post a letter. In 1830 it would take the average worker 40 minutes to earn the equivalent amount. Imagine how you would feel if you were notified that there was a letter waiting for you at the Post Office and you queued for the right to submit perhaps half a day's wages to finally claim a letter notifying you that you may have been a winner in ye olde publisher's sweepstakes!

It was obvious to many Englishmen in the 1830 s that the postal system was badly in need of reform, and an educator named Rowland Hill was eventually asked to chair a postal reform commission. Hill's commission recommended a uniform penny postage rate for a local single weight letter, to be prepaid by the sender. It suggested that the loss of revenue per letter would be offset by increased usage and efficiency and by the benefits to society that would accrue. It was right: mail volume in England went from 77 million letters in 1840 to 640 million a few decades later.

For prepayment Hill suggested three possible schemes : payment could be made in cash to the clerk, the mailer could buy prestamped envelopes or letter sheets, or gummed stamps could be provided. Prestamped envelopes and letter sheets came into use, but the first few designs, which were overly elaborate, were ridiculed by the public. As a result, the "pregummed stamp" carried the day.

Thus was born the world's first postage stamp. The invention of the postage stamp in 1840 was a reflection of the times : the extension of a government service to the masses was part of the general spirit of reform which prevailed in the age. The presses rolled out 500000 stamps a day and still could not meet the demand. The people cheered in the streets on 6 May to celebrate their access to the post. More than 68 million penny blacks (the first postage stamp) were eventually used, and they are not rare today. In recognition of the stamp's birth in Great Britain, the Universal Postal Union, which is an international organisation regulating mail between countries, has allowed Great Britain to be the only country in the world that does not need to show the name of the country on its postage stamps; a cameo of the ruling monarch is sufficient without the words Great Britain. Brazil was the second country to introduce stamps, in 1843. The United States came along later in 1847.

No one knows how long it took before the first person decided that it would be interesting to collect these tiny, colourful bits of paper from around the world, but there is evidence of organised stamp collecting activity by the 1870s. Philately has since grown to be one of the world's most popular hobbies.

Stamp collecting takes many forms. The traditional collector selects a country or geographic area and tries to get one of everything. However, one of the most popular branches of philately is topical, or thematic, collecting, in which it is the subject matter portrayed on the stamp that arouses the interest of the collector. Medicine is a very popular topic. Topics that can be collected range from the mundane, such as cats or trains, to the esoteric, such as people who have been beheaded or stamps picturing pineapples. Topical collecting has one great advantage over traditional philately - namely, that it is usually much cheaper. Most of the stamps shown on the cover of this journal cost no more than a dollar, and many are worth only pennies.

Topics for stamp issues are chosen by postal administrations for many reasons. Those countries of the world that have what are regarded as conservative stamp issuing policies generally
Medical Center, New Hyde Park, New York 11042 , USA R A Greenwald 
select people or themes that are relevant to their own land and culture. Heads of state and other prominent personages, important cultural institutions, customs and folkways, objects from the arts and sciences, etc, are all popular subjects. Stamps have been used to promote political themes - for example, boundary disputes - and to raise funds for charities.

In theory (and practice) the postage stamp is a tiny billboard that can readily be disseminated to the masses; stamps are widely distributed and cross borders easily. In literate countries where most of the populace uses the post a message can be transmitted on the stamp that will be seen by millions and at rather low cost; the United States Postal Service, for example, pays less than $\$ 2.00$ per thousand for the stamps that it resells at 29 cents each.

Thus it is not surprising that stamps have often been used to publicise health themes such as alcoholism, drug abuse, family planning, etc. In the past two decades the World Health Organisation has mounted a number of campaigns of coordinated effort among many countries, all of which issue a stamp on the same theme, preferably on World Health Day (generally 7 April). Themes from the past include malaria control (1962), heart disease (1972), blindness (onchocerciasis and trachoma, 1976), World Rheumatism Year (1977), and hypertension (1978); 1980 was the year for tobacco control.

Creating suitable art work for a stamp is a very sophisticated process. The image area is very small, the choice of colours is limited, and the technicalities of printing are very sophisticated. The artist must balance all of this with the desire to make the stamp both attractive and attention getting. Drama certainly plays a part; the stamps on the cover of this issue show ample evidence of smoke engulfing the user, black lungs, premature aging, etc. A viewer of a stamp such as the issue from Bulgaria (the stamp with the black cloud over the lungs and the inscription in Cyrillic) cannot help but notice the message. Many stamps against alcohol, drugs, and smoking use a death theme depicting skulls, crosses, and similar macabre illustrations.

In the industrialised nations patrons of the postal system are exposed to the messages portrayed on the stamps they use, but these people also get the message from print media, television, etc. The most exploited victims of public health scourges such as tobacco are the poorest socioeconomic classes, to whom it is hard to deliver the message. Superficially, one might think that the postage stamp is a useful medium. Alas, many countries that issue thematic stamps are $98 \%$ illiterate, and some in fact are even uninhabited. Unfortunately, many Third World nations exploit the stamp collectors of the world by choosing subjects that will appeal primarily to collectors abroad and thus enhance the issuing countries' foreign exchange. The stamps are often printed in Europe and shipped directly to US dealers without even entering the putative country of origin. When a Third World nation with hardly any telephones issues stamps showing satellites, space stations, and lasers the message is clearly not intended for the home audience. Many of the stamps showing the perils of smoking were indeed poor messengers; the people who needed the lesson the most rarely got to see the message. Nevertheless, since stamps need to be issued anyway, it certainly behooves the postal administrations of such countries to utilise the capacity of the common postage stamp to disseminate messages such as the perils of smoking.

The stamp sheets containing the Israeli stamp reproduced on the cover include the message (in Hebrew and English): "life is sweeter without smoking." The Brazilian stamp shown on the cover was one of a series of three stamps, collectively named "fight against drugs," issued on 7 April (World Health Day) in 1991; the two other stamps depict themes against alcohol and psychotropic drug use. For further background information readers may wish to consult the cover essay by Dr Fames Lutschg in the first issue of the journal.-ED

The costs of producing the cover of this issue were defrayed by generous contributions from the Michigan Division of the American Cancer Society and from the American Lung Association of Michigan. 